\title{
Decomposer diversity and identity influence plant diversity effects on ecosystem functioning
}

\author{
Nico Eisenhauer, ${ }^{1,2,5}$ Peter B. Reich, ${ }^{1,3}$ and Forest Isbell ${ }^{4}$ \\ ${ }^{1}$ Department of Forest Resources, University of Minnesota, St. Paul, Minnesota 55108 USA \\ ${ }^{2}$ Technische Universität München, Department of Ecology and Ecosystem Management, 85354 Freising, Germany \\ ${ }^{3}$ Hawkesbury Institute for the Environment, University of Western Sydney, Penrith, New South Wales 2751 Australia \\ ${ }^{4}$ Department of Ecology, Evolution, and Behavior, University of Minnesota, St. Paul, Minnesota 55108 USA
}

\begin{abstract}
Plant productivity and other ecosystem functions often increase with plant diversity at a local scale. Alongside various plant-centered explanations for this pattern, there is accumulating evidence that multi-trophic interactions shape this relationship. Here, we investigated for the first time if plant diversity effects on ecosystem functioning are mediated or driven by decomposer animal diversity and identity using a double-diversity microcosm experiment. We show that many ecosystem processes and ecosystem multifunctionality (herbaceous shoot biomass production, litter removal, and $\mathrm{N}$ uptake) were affected by both plant and decomposer diversity, with ecosystem process rates often being maximal at intermediate to high plant and decomposer diversity and minimal at both low plant and decomposer diversity. Decomposers relaxed interspecific plant competition by enlarging chemical (increased $\mathrm{N}$ uptake and surface-litter decomposition) and spatial (increasing deeproot biomass) habitat space and by promoting plant complementarity. Anecic earthworms and isopods functioned as key decomposers; although decomposer diversity effects did not solely rely on these two decomposer species, positive plant net biodiversity and complementarity effects only occurred in the absence of isopods and the presence of anecic earthworms. Using a structural equation model, we explained $76 \%$ of the variance in plant complementarity, identified direct and indirect effect paths, and showed that the presence of key decomposers accounted for approximately three-quarters of the explained variance. We conclude that decomposer animals have been underappreciated as contributing agents of plant diversityecosystem functioning relationships. Elevated decomposer performance at high plant diversity found in previous experiments likely positively feeds back to plant performance, thus contributing to the positive relationship between plant diversity and ecosystem functioning.
\end{abstract}

Key words: biodiversity-ecosystem functioning; competition; complementarity effect; habitat space; litter decomposition; multi-trophic interactions; root depth distribution; selection effect; soil feedback; soil mutualists.

\section{INTRODUCTION}

Biodiversity is currently decreasing at an unprecedented rate due to multiple anthropogenic stressors (Butchart et al. 2010). There is accumulating evidence suggesting that this process fundamentally threatens ecosystem processes and services mankind relies on (Balvanera et al. 2006, Cardinale et al. 2011, Isbell et al. 2011). Despite some criticism (e.g., Wardle and Jonsson 2010), biodiversity experiments reveal general relationships between diversity and ecosystem functioning (Schmid and Hector 2004, Duffy 2009). While the significance and direction of biodiversity-ecosystem functioning relationships is widely accepted, current

Manuscript received 17 December 2011; revised 19 April 2012; accepted 19 April 2012. Corresponding Editor: M. C. Rillig.

${ }^{5}$ Present address: Technische Universität München, Department of Ecology and Ecosystem Management, 85354 Freising, Germany. E-mail: nico.eisenhauer@web.de research examines the underlying mechanisms (e.g., Fornara and Tilman 2009, Maron et al. 2011, Reich et al. 2012). Recent studies indicate that multi-trophic interactions shape or determine the relationship between plant diversity and ecosystem functioning, emphasizing the relevance of soil pathogens (Petermann et al. 2008, Maron et al. 2011, Schnitzer et al. 2011), bacteria that promote plant growth (Latz et al. 2012), insect herbivores (Mulder et al. 1999), arbuscular mycorrhizal fungi (AMF; van der Heijden et al. 1998, Klironomos et al. 2000, Wagg et al. 2011), and decomposers (Naeem et al. 2000, Eisenhauer et al. 2008, Eisenhauer 2012). These findings go beyond the plant-centered view (Bever et al. 2010, Miki et al. 2010) taken in early biodiversityecosystem functioning studies and suggest the importance of performing biodiversity-ecosystem functioning experiments in a multi-trophic, and thus, likely more realistic context (Naeem et al. 2000, Bruno et al. 2008).

While species-poor plant communities may accumulate pathogens and experience mostly detrimental soil 
feedback effects (Maron et al. 2011, Schnitzer et al. 2011), species-rich plant communities were hypothesized to support mutualists exerting mostly positive feedbacks on plant community productivity (Eisenhauer 2012). This idea originated due to the increasing awareness of significant long-term effects of plant diversity on decomposer density and diversity (Scherber et al. 2010, Eisenhauer et al. 2011). Changes in decomposer diversity may, in turn, significantly impact ecosystem processes, such as nutrient cycling and plant productivity (Loreau 2001, Mikola et al. 2002, Heemsbergen et al. 2004, Tiunov and Scheu 2005, Miki et al. 2010), though effects are presumed to be most pronounced at the lower end of the diversity gradient (Bardgett and Wardle 2010). According to the soil feedback maturation hypothesis (N. Eisenhauer, S. Scheu, and P. B. Reich, unpublished manuscript), increasing plant diversity effects over time (Cardinale et al. 2007, Fargione et al. 2007) may be partly due to the delayed response of soil biota to plant community composition. This suggests that plant diversity effects on ecosystem functioning depend on the composition and diversity of the decomposer community (Naeem et al. 2000, Miki et al. 2010). To our knowledge, no study has manipulated plant and decomposer diversity simultaneously in a terrestrial ecosystem.

Here we crossed a herbaceous plant diversity gradient (one, two, and four plant species) with a decomposer animal diversity gradient (one, two, and four decomposer species) in a laboratory microcosm experiment in a forest model system in order to investigate if (1) plant diversity effects on ecosystem functioning depend on decomposer diversity and identity (Naeem et al. 2000, Loreau 2001, Miki et al. 2010) with stronger plant diversity effects in the presence of diverse decomposer communities (Eisenhauer 2012). More specifically, we asked whether (2) decomposers increase plant complementarity (Eisenhauer 2012), and whether (3) decomposer diversity and identity increase plant diversity effects by enhancing litter decomposition, $\mathrm{N}$ uptake, and rooting depth (Eisenhauer 2012). Note that previous multitrophic biodiversity-ecosystem functioning studies have often manipulated plant diversity and the presence, but not the diversity, of other trophic levels.

\section{Materials}

\section{Experimental setup}

We set up microcosms consisting of Polyvinyl chloride (PVC) tubes (inner diameter $10 \mathrm{~cm}$, height $25 \mathrm{~cm}$ ) covered by a $5-\mathrm{mm}$ mesh at the bottom to allow drainage of water. A plastic barrier $(10 \mathrm{~cm}$ height $)$ at the top of the microcosm reduced the escape of decomposers from experiment containers. The soil ( $\mathrm{pH}$ 5.76, carbon concentration $1.57 \%$, nitrogen concentration $0.091 \%$, Cto- $\mathrm{N}$ ratio 17.2; gravimetric water content $15 \%$ at the start of the experiment) was taken from the field site of the B4WarmED experiment and the functional tree diversity experiment at the Cloquet Forestry Center
(Cloquet, Minnesota, USA; experiment descriptions available online). ${ }^{6}$

A total of 45 microcosms were filled with $5 \mathrm{~cm}$ of perlite at the bottom to allow drainage of water and prevent the escape of decomposers, and then with $2 \mathrm{~kg}$ (fresh weight; total height of the soil column $20 \mathrm{~cm}$ ) of sieved $(1 \mathrm{~cm})$, defaunated (two freeze-thaw cycles), and homogenized soil. Defaunation by freezing kills soil meso- and macrofauna (the manipulated soil animal groups in the present experiment), while microorganisms and microfauna largely survive (Huhta et al. 1989). To track nutrient assimilation by the plants, $0.50 \mathrm{~g}$ of dried, ${ }^{15} \mathrm{~N}$-labeled Lolium perenne root litter material (30 atom $\%{ }^{15} \mathrm{~N}$ ) was cut into pieces $<1 \mathrm{~mm}$ and homogeneously mixed into the upper $5 \mathrm{~cm}$ of the soil of each microcosm.

We pre-grew five different plant species belonging to three plant functional groups (forbs [broadleaved herbs], legumes [Fabaceae], and grasses [Poaceae]) in separate trays: Calamagrostis canadensis (grass), Lathyrus venosus (legume), Phleum pratense (grass), Plantago lanceolata (forb), and Trifolium pratense (legume). All five plant species are common at the Cloquet field site (Eisenhauer et al. 2012). Calamagrostis canadensis and L. venosus were purchased from Prairie Moon Nursery (Winona, Minnesota, USA), whereas $P$. pratense, $P$. lanceolata, and T. pratense were purchased from RiegerHofmann GmbH (Blaufelden-Raboldshausen, Germany). We were unable to collect seeds in the field and believe that potential ecotypic variation due to purchasing some plant species from a German seed source did not influence the outcome and conclusions of our study. Four plant individuals (4 weeks old, height $3-8 \mathrm{~cm}$ ) were transplanted into each microcosm, creating three plant species richness treatments (one, two, and four plant species). We aimed at transplanting seedlings of similar size; however, different plant species varied in their growth form. Plant monocultures had four individuals of one species, two species mixtures had two individuals of two species (planted in an alternate pattern), and four species mixtures had one individual per plant species. We randomly assembled 20 different plant communities and each plant species occurred in 21 different microcosms (Appendix: Tables A1 and A2). This means that even the highest plant species richness level (four species mixtures) was represented by five unique plant community composition treatments (Appendix: Table A1).

In addition to the herbaceous plant species richness gradient, we planted one white spruce sapling (Picea glauca) into the centre of each microcosm as a phytometer. This tree species was chosen since a herbaceous plant diversity gradient in a forest ecosystem was simulated (field site of the B4WarmED experiment) and in order to investigate plant competition at the

${ }^{6}$ http://cfc.cfans.umn.edu/Research/index.htm 
individual level in a standardized way (Eisenhauer et al. 2009). The herbaceous plant community is of particular importance for the functioning of forest ecosystems (Gilliam 2007), which is why we manipulated herbaceous plant diversity and treated white spruce as a phytometer in the present experiment. White spruce saplings were purchased from Itasca Greenhouse (Cohasset, Minnesota, USA) and were $18.2 \pm 0.2 \mathrm{~cm}$ (mean $\pm \mathrm{SE}$ ) tall at the start of the experiment. The saplings were kept at $5^{\circ} \mathrm{C}$ prior to the start of the experiment to induce dormancy and to assess treatment effects during the physiologically active time of sprouting.

A layer of litter $(2.5 \mathrm{~g}$, mixed litter material collected at the field site of the Cloquet experimental field site; dried at $60^{\circ} \mathrm{C}$ for $3 \mathrm{~d}$ and cut into pieces $\sim 3 \mathrm{~cm}$ in length; C concentration $31.04 \%$, N concentration $1.05 \%$, C-to$\mathrm{N}$ ratio 30) was placed on the soil surface to simulate natural conditions. The leaf litter material consisted mainly of Populus tremuloides, Aster macrophyllus, and Carex pensylvanica.

The microcosms were placed in a temperaturecontrolled growth chamber at a day/night regime of $16 / 8 \mathrm{~h}$ and $16 / 12^{\circ} \pm 1^{\circ} \mathrm{C}$ (mean temperature $14.67^{\circ} \mathrm{C}$ ). This temperature corresponds to the mean temperature of the growing season (ca. April to October) at the Cloquet experimental field site from 2008 to 2010 (R. Rich, unpublished data).

In addition to the plant species richness gradient, we orthogonally simulated a decomposer species richness gradient using five common and functionally dissimilar meso- and/or macrodecomposer species: Aporrectodea caliginosa (Annelida), Cyclindroiulus sp. (Diplopoda), Lumbricus terrestris (Annelida; see Plate 1), Onychiurus sp. (Collembola), and Trachelipus sp. (Isopoda). Collembolans and earthworms were purchased from commercial suppliers, while diplopods and isopods were collected in a mixed-deciduous forest stand at the St. Paul campus of the University of Minnesota (Minnesota, USA). All decomposer species were kept in the experimental soil for approximately two weeks prior to beginning of the experiment (Fründ et al. 2010). The decomposer species used in the study represent dominant decomposer groups at the Cloquet experimental field site (N. Eisenhauer, unpublished data). Depending on the experimental design shown in Appendix: Table A1, we added two subadult individuals of $A$. caliginosa $(0.84 \pm 0.03 \mathrm{~g}$ fresh mass with gut content), four individuals of Cyclindroiulus, one adult individual of Lumbricus terrestris (LUM; $4.04 \pm 0.13 \mathrm{~g}$ fresh mass with gut content), 20 mediumsized individuals of Onychiurus, and/or two individuals of Trachelipus to the microcosms to create three decomposer species richness levels (one, two, and four decomposer species). Analogous to the design of the plant species richness gradient, we randomly assembled 20 different decomposer communities and each decomposer species occurred in 21 different microcosms (Appendix: Table A1). This resulted in 3 plant species richness levels $\times 3$ decomposer species richness levels $\times$ 5 replicates $=45$ unique experimental units in total (Appendix: Tables A1 and A2). While plant species richness and decomposer biomass were not significantly correlated at the start of the experiment $(r=-0.03, P=$ $0.83)$, initial decomposer biomass was positively and significantly related to decomposer species richness $(r=$ $0.61, P<0.001)$; however, standardization of decomposer biomass would have resulted in unnaturally high densities of collembolans, diplopods, and isopods. The additive design to create the decomposer diversity gradient does not allow calculating complementarity and selection effects for decomposers. Although plant diversity and decomposer diversity levels were rather low (one to four species), they represent realistic small scale plant (N. Fisichelli, unpublished data) and decomposer macrofauna diversity levels (N. Eisenhauer, unpublished data) at the simulated Cloquet experimental field site.

Light intensity varied between 580 and 900 $\mu \mathrm{E} \cdot \mathrm{m}^{-2} \cdot \mathrm{s}^{-1}$ depending on the location in the growth chambers. To avoid chamber edge effects, microcosms were randomized every week within each chamber. The microcosms were irrigated four times per week with deionized water and the volume was increased from 60 $\mathrm{mL}$ (weeks 1-3) to $120 \mathrm{~mL}$ (weeks 4-14) due to increasing water demands by the growing plants. All microcosms received the same amount of water allowing for treatment-induced differences in water availability.

\section{Sampling}

After 14 weeks, we destructively harvested the experiment. We carefully collected the remaining surface-litter material and removed the soil attached to it to calculate surface-litter removal. Then, we harvested the shoot material of each plant species separately by cutting shoots at the soil surface. Shoot and litter material were dried at $70^{\circ} \mathrm{C}$ for $3 \mathrm{~d}$. Three soil cores $(2$ $\mathrm{cm}$ in diameter, $6 \mathrm{~cm}$ deep) per microcosm were taken to measure soil microbial biomass. The remaining soil was removed from the microcosms and decomposers were extracted from the upper $6 \mathrm{~cm}$ by heat (Kempson et al. 1963). The remaining soil (lower $\sim 14 \mathrm{~cm}$ of the soil column) was carefully checked for soil animals; i.e., the soil core was fragmented into pieces of $<5 \mathrm{~mm}$ in diameter and sift through for $\sim 10$ min per microcosm. All decomposers were transferred into $70 \%$ ethanol, counted, and weighed (earthworms and diplopods). Thereby, the success of the decomposer treatments was verified; only one replicate had to be excluded from the analyses due to lack of decomposers at the end of the experiment and missing signs of decomposer activity (Appendix: Tables A1 and A2). Roots were washed out of the soil of each layer (upper $6 \mathrm{~cm}$ and lower $14 \mathrm{~cm}$ ) using a $1-\mathrm{mm}$ mesh, dried at $70^{\circ} \mathrm{C}$ for $3 \mathrm{~d}$ and weighed; it was not possible to sort roots by plant species. 


\section{Soil microbial analyses}

Soil subsamples for the measurement of soil microbial biomass were sieved $(2 \mathrm{~mm}$; Anderson and Domsch 1978). Microbial biomass $C$ of $\sim 5 \mathrm{~g}$ soil (fresh mass) was measured using an $\mathrm{O}_{2}$-microcompensation apparatus (Scheu 1992). Substrate induced respiration was calculated from the respiratory response to D-glucose for $10 \mathrm{~h}$ at $22^{\circ} \mathrm{C}$ (Anderson and Domsch 1978). Glucose was added according to preliminary studies to saturate the catabolic enzymes of microorganisms $(20 \mathrm{mg} / \mathrm{g}$ dry mass solved in $400 \mu \mathrm{L}$ deionized water). The mean of the lowest three readings within the first $10 \mathrm{~h}$ was taken as maximum initial respiratory response (MIRR; $\mu$ l $\mathrm{O}_{2} \cdot \mathrm{h}^{-1} \cdot \mathrm{g}^{-1}$ soil dry mass) and microbial biomass ( $\mu \mathrm{g}$ $\mathrm{C} / \mathrm{g}$ soil dry mass) was calculated as $38 \times$ MIRR.

\section{Phytometer ${ }^{15} \mathrm{~N}$ analyses}

White spruce served as phytometer species and was grown in all microcosms. Approximately $1.3 \mathrm{mg}$ of the powdered (ground) white spruce needles was weighed into tin capsules to determine a proxy measure for $\mathrm{N}$ uptake from root litter. ${ }^{15} \mathrm{~N}$ signatures were determined by a coupled system consisting of an elemental analyzer (NA 1500; Carlo Erba, Milan. Italy) and a gas isotope mass spectrometer (MAT 251; Finnigan, Bremen, Germany). For ${ }^{15} \mathrm{~N}$, atmospheric $\mathrm{N}_{2}$ served as the primary standard, and acetanilide $\left(\mathrm{C}_{8} \mathrm{H}_{9} \mathrm{NO}\right.$; Merck, Darmstadt, Germany) was used for internal calibration.

\section{Complementarity and selection effects}

Complementarity and selection effects were quantified by Loreau and Hector's (2001) additive partition of the net biodiversity effect (NBE) as follows:

$$
\mathrm{NBE}=S \overline{\Delta \mathrm{RY}} \bar{M}+S \operatorname{cov}(\Delta \mathrm{RY}, M)
$$

where $S$ is species richness, $\Delta R Y$ is the difference between the observed and expected relative yield, and $M$ is monoculture productivity. In Eq. 1, the first (average) term is the complementarity effect and the second (covariance) term is the selection effect. The observed relative yield for species $i$ was calculated as $Y_{\mathrm{o} i} /$ $M_{i}$, where $Y_{\mathrm{o} i}$ and $M_{i}$ are the observed mixture and monoculture yields for species $i$, respectively. The expected relative yield was taken as the planted relative abundance of each species. These measures summarize many types of interactions. A positive complementarity effect indicates that on average interspecific interactions are more favorable than intraspecific interactions (e.g., due to niche partitioning or interspecific facilitation). A negative complementarity effect indicates that, on average, intraspecific interactions are more favorable than interspecific interactions (e.g., due to interspecific interference competition). A positive or negative selection effect indicates that the most or least productive species in monocultures overyielded most in mixtures (i.e., benefits most from interspecific interactions compared to intraspecific interactions). The additive parti- tioning approach could only be applied to plant diversity effects since an additive design was chosen to create the decomposer animal diversity gradient.

\section{Ecosystem multifunctionality}

In order to test plant diversity and decomposer diversity effects on ecosystem multifunctionality (e.g., Hector and Bagchi 2007), we used common ecosystem functions in grassland biodiversity experiments (herbaceous shoot biomass, litter removal, and $\mathrm{N}$ uptake) and calculated the standardized response (SRE) of each variable (values between 0 and 1) using the following equation:

$$
\operatorname{SRE}_{i}=\left(X_{i}-\operatorname{Min}\left(v_{j}\right)\right) /\left(\operatorname{Max}\left(v_{j}\right)-\operatorname{Min}\left(v_{j}\right)\right)
$$

where $X_{i}$ is the value measured in each pot $i, \operatorname{Min}\left(v_{j}\right)$ is the minimal value of the response variable $j$, and $\operatorname{Max}\left(v_{j}\right)$ is the maximal value of the response variable. Maximal values of herbaceous shoot biomass, litter removal, and $\mathrm{N}$ uptake thus received a 1 , indicating high levels of these ecosystem functions. Analogously, minimal values received a 0 , indicating low levels of ecosystem functioning. Then, we calculated the mean of the three ecosystem functions (values between 0 and 1) as proxy measure for ecosystem multifunctionality giving each ecosystem function the same weight (Mouillot et al. 2011).

\section{Statistical analyses}

Data were $\log _{10}$-transformed to meet the requirements of Analysis of Variance (ANOVA; normality and homoscedasticity of errors), if necessary (indicated by $\log _{10}$ ). Means ( \pm standard error) presented in text and figures were calculated using non-transformed data. ANOVA was performed to analyze the effects of plant species richness (one, two, and four species), decomposer species richness (one, two, and four species), plant species identity ( 0 and 1$)$, decomposer species identity $(0$ and 1), plant community composition (20 different communities), decomposer community composition (20 different communities), and the two-way interactions of these sources of variation on the response variables surface-litter removal (as proxy for litter decomposition), soil microbial biomass (as proxy for soil microbial functioning), herbaceous plant shoot biomass ( $\log _{10}$; representing the most frequently measured ecosystem function in plant diversity experiments; Eisenhauer 2012), spruce shoot biomass $\left(\log _{10}\right.$; as proxy for individuals' performance; Eisenhauer et al. 2009), total root biomass, total plant biomass (herbs and spruce), shoot-to-root ratio, root depth distribution (all as proxy for plant competition and biomass partitioning; Bessler et al. 2009), net plant diversity effect (plant species richness levels 2 and 4), plant complementarity effect, plant selection effect, ${ }^{15} \mathrm{~N}$ signature in white spruce needles $\left(\log _{10}\right.$; as proxy for $\mathrm{N}$ uptake; Partsch et al. 2006), and ecosystem multifunctionality. In separate 
analyses, we included initial spruce height as covariate; this did, however, not improve the models and/or change the results (not shown). Moreover, in order to relate decomposer identity effects (presence of anecic earthworms and isopods) on net biodiversity effects to interactions between key decomposer species and plant species, we tested decomposer identity effects on the relative yield of individual plant species (one-way ANOVAs).

Effects of plant species richness (PSR) and identity were tested against the variance explained by plant community composition to statistically separate diversity from composition effects. Analogously, decomposer species richness (DSR) and identity effects were tested against decomposer community composition. After fitting an initial model with PSR, DSR, PSR $\times$ DSR, plant community composition, and decomposer community composition, we added plant and decomposer identity effects and respective interactions to separate models, and we included them into the overall model if they increased its fit to the data (based on the comparing of AICs; threshold $\triangle \mathrm{AIC}=2$ ). Only results of the final models are presented below (see Appendix: Table A3). PSR and DSR were tested as categorical (cat) and linear (lin) terms, respectively (Milcu et al. 2008).

We did not correct for multiple statistical tests considering the mathematical and logical argumentation by Moran (2003). From a mathematical point of view, given that ecological studies are often highly variable and replicated in low numbers, they result in more high $P$ values and only few low $P$ values, therefore decreasing the probability of significant multiple statistical tests, although higher $P$ values may mirror significance more realistically. Moreover, some corrections do not account for the number of significant tests. Logically, it would be highly questionable to penalize studies reporting more response and explanatory variables in comparison to those only reporting few dependent variables. All analyses were performed using SAS 9.1 (SAS Institute 2003).

In addition to the ANOVA approach, we used structural equation modeling (SEM) to identify the main variables and effect pathways influencing the plant complementarity effect on plant productivity as affected by plant diversity and decomposer diversity and identity. This was done due to the prime role of complementarity effects in the biodiversity ecosystemfunctioning relationship (Cardinale et al. 2007, Fargione et al. 2007). SEM allows testing the strength of direct and indirect relationships between variables in a multivariate approach (Grace 2006). We used PSR (Cardinale et al. 2007) and the significant independent variables identified using the ANOVA approach (presence of anecic earthworms and isopods; exogenous variables), as well as the dependent variables "proportion of deep roots," "surface-litter biomass," and "N uptake" as potential indirect pathways (endogenous variables) in order to explain how the experimental treatments could affect the complementarity effect. These indirect pathways have been proposed before (Eisenhauer 2012). All exogenous variables tested in the ANOVA approach hypothetically influence plant complementarity (Eisenhauer 2012); however, given the limited amount of replicates, we only considered significant exogenous variables in the SEM which had been identified in the ANOVA approach. The adequacy of the model was determined via $\chi^{2}$ tests and AIC. Nonsignificant $\chi^{2}$ tests $(P>0.05)$ and low AIC values indicate that the model cannot be rejected as a potential explanation of the observed covariance structure (Grace 2006). Due to the complete factorial design, we expected PSR, presence of anecic earthworms, and isopods to be uncorrelated. Model modification indices and stepwise removal of unimportant relationships were used to improve the models (based on the model fit indices; Grace 2006). In separate SEMs, the significance of DSR (exogenous variable) and microbial biomass (endogenous variable) were tested, but the respective final models never did fit the data as well as the model without those variables (not shown). Unstandardized path coefficients are given in the Appendix: Fig. A1. Similarly, we performed SEM to identify the main variables affecting ecosystem multifunctionality using the exogenous variables PSR, DSR, presence of $T$. pratense, $P$. pratense, and L. terrestris. Unstandardized path coefficients are given in the Appendix: Fig. A2. SEM was performed using Amos 5 (Amos Development Corporation, Crawfordville, Florida, USA; Arbuckle 2003).

\section{RESUlTS}

\section{Litter removal and soil microbial biomass}

Consistent with our first hypothesis, the DSR influenced the effect of PSR on decomposition. The amount of remaining litter on the soil surface (mean 0.95 $\mathrm{g} /$ microcosm; the inverse of litter removal) decreased significantly with DSR (linear $F_{1,15}=16.79, P=0.001$ ); however, this effect depended on PSR with highest litter removal at high decomposer (four decomposer species) and intermediate-to-high plant diversity (two and four plant species; $\mathrm{PSR}_{\operatorname{lin}} \times \mathrm{DSR}_{\operatorname{lin}}$ interaction, $F_{1,42}=6.97, P$ $=0.046$; Fig. 1A). Moreover, the amount of remaining litter was significantly lower in the presence of anecic earthworms than in their absence $\left(-79 \% ; F_{1,15}=41.47, P\right.$ $<0.001)$.

Microbial biomass (mean $326 \mu \mathrm{g} / \mathrm{g}$ soil dry mass) decreased with increasing PSR (main effect of PSR, linear $\left.F_{1,18}=6.60, P=0.019\right)$ in the presence of two and four decomposer species, whereas it increased slightly with increasing PSR in the presence of one decomposer species $\left(\mathrm{PSR}_{\operatorname{lin}} \times \mathrm{DSR}_{\operatorname{lin}}\right.$ interaction, $F_{1,42}=6.02, P=$ 0.058; Fig. 1B). Moreover, microbial biomass was reduced significantly in the presence of $P$. lanceolata $\left(-30 \% ; F_{1,18}=6.12, P=0.024\right)$. 

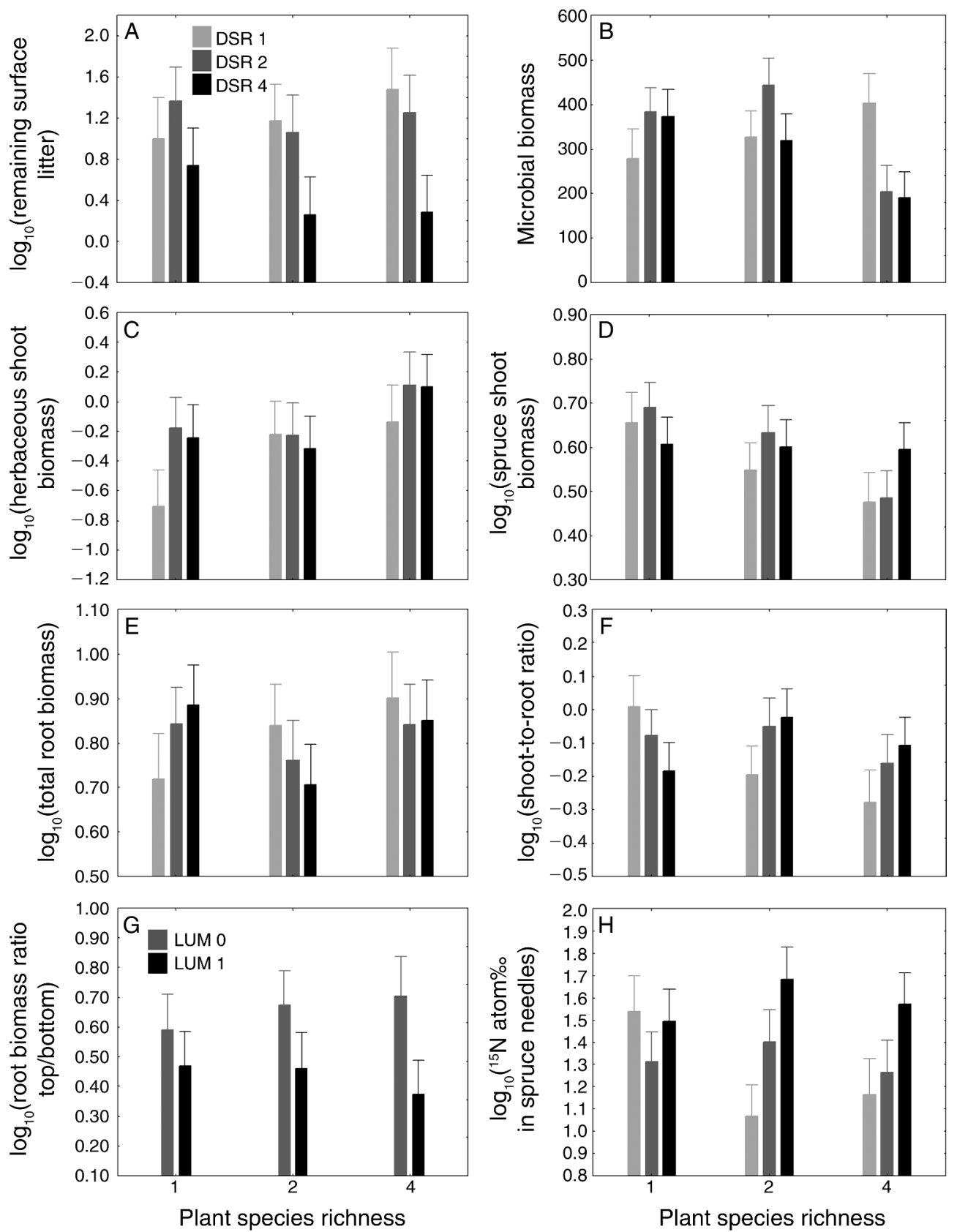

FIG. 1. Effects (mean $+\mathrm{SE}$ ) of herbaceous plant species richness (PSR; one, two, and four species) and decomposer species richness (DSR; one, two, and four species) on (A) remaining surface litter (measured in grams before log-transformation) (PSR ${ }^{\text {ns }}$, $\mathrm{DSR}^{* * *}$, PSR $\left.\times \mathrm{DSR}^{*}\right),(\mathrm{B})$ soil microbial biomass $\left(\mu \mathrm{g} \mathrm{C}_{\mathrm{mic}} / \mathrm{g}\right.$ soil dry mass) $\left(\mathrm{PSR}^{*}, \mathrm{DSR}^{\mathrm{ns}}\right.$, PSR $\times$ DSR $\left.\dagger\right),(\mathrm{C})$ herbaceous shoot biomass $(\mathrm{g})\left(\mathrm{PSR}^{* * *}, \mathrm{DSR}^{\mathrm{ns}}, \mathrm{PSR} \times \mathrm{DSR}^{\mathrm{ns}}\right),(\mathrm{D})$ white spruce shoot biomass $(\mathrm{g})\left(\mathrm{PSR}^{*}, \mathrm{DSR}^{\mathrm{ns}}, \mathrm{PSR} \times \mathrm{DSR} \dagger\right),(\mathrm{E})$ total root biomass $(\mathrm{g})\left(\mathrm{PSR}^{\mathrm{ns}}, \mathrm{DSR}^{\mathrm{ns}}, \mathrm{PSR} \times \mathrm{DSR}^{\mathrm{ns}}\right),(\mathrm{F})$ total shoot-to-root ratio $\left(\mathrm{PSR}^{\mathrm{ns}}, \mathrm{DSR}^{\mathrm{ns}}, \mathrm{PSR} \times \mathrm{DSR}^{*}\right)$, and $(\mathrm{H}){ }^{15} \mathrm{~N}$ signature in white spruce needles (atom\%) $\left(\mathrm{PSR}^{\mathrm{ns}}, \mathrm{DSR}^{*}, \mathrm{PSR} \times \mathrm{DSR} *\right)$. (G) Effects of plant species richness and presence of the anecic earthworm species Lumbricus terrestris (LUM; 0, absent; 1, present) on root depth distribution $\left(\mathrm{PSR}^{\mathrm{ns}}, \mathrm{DSR}^{\mathrm{ns}}, \mathrm{PSR} \times \mathrm{DSR} \dagger\right)$.

$* P<0.05 ; * * * P<0.001 ; \dagger P<0.1 ;$ ns, not significant.

\section{Plant productivity and ${ }^{15} \mathrm{~N}$ signature}

Plant performance measures partly supported our first hypothesis: Although we found no significant interactions between PSR and DSR on herbaceous shoot biomass (Fig. 1C) and total root biomass (Fig. 1E), herbaceous shoot biomass was highest at high PSR and intermediate to high DSR and lowest at both low PSR and DSR. Significant or marginally significant interactive effects of PSR and DSR or decomposer identity on spruce shoot biomass (PSR $\times$ DSR interaction, $P<0.1$; 
Fig. 1D), shoot-to-root ratio (PSR $\times$ DSR interaction, $P$ $<0.05$; Fig. $1 \mathrm{~F}$ ), and root depth distribution (PSR $\times$ Lumbricus terrestris $[\mathrm{LUM}]$ interaction, $P<0.1$; Fig. $1 \mathrm{G})$ indicate that decomposers altered competitive interactions between plants and belowground biomass allocation (Bessler et al. 2009).

Shoot biomass of herbaceous plants (mean $1.07 \mathrm{~g} /$ microcosm) increased significantly with PSR (linear $F_{1,16}$ $=15.01, P=0.001$; Fig. $1 \mathrm{C})$, while DSR had no significant effects $(P>0.20)$. Moreover, herbaceous shoot biomass increased significantly in the presence of $P$. pratense $\left(+94 \% ; F_{1,16}=8.89, P=0.009\right)$, but decreased in the presence of $C$. canadensis $\left(-26 \% ; F_{1,16}=22.86, P\right.$ $<0.001)$. Decomposer identity also had significant effects on herbaceous shoot biomass, with increased biomass in the presence anecic earthworms $(+250 \%$; $\left.F_{1,14}=22.22, P<0.001\right)$, and decreased biomass in the presence of diplopods $\left(-14 \% ; F_{1,14}=7.26, P=0.018\right)$. All other factors had no significant effects on herbaceous shoot biomass (all $P>0.20$ ). In contrast to herbaceous shoot biomass, spruce shoot biomass (mean $4.11 \mathrm{~g})$ decreased significantly with increasing PSR (linear $F_{1,17}=6.82, P=0.018$; Fig. 1D) indicating increasing plant competition; however, this effect was true only for decomposer communities with one and two species $\left(\mathrm{PSR}_{\text {lin }} \times \mathrm{DSR}_{\text {lin }}\right.$ interaction, $F_{1,42}=5.79, P=$ 0.061 ), whereas spruce biomass was little affected by PSR in the presence of four decomposers. All other factors had no significant effects on spruce shoot biomass (all $P>0.20$ ).

Total root biomass (mean $7.38 \mathrm{~g}$ ) was not significantly affected by PSR and DSR $(P>0.20$; Fig. 1E); however, it increased in the presence of $P$. pratense $\left(+63 \% ; F_{1,18}=\right.$ $20.72, P<0.001)$ and anecic earthworms $\left(+74 \% ; F_{1,16}=\right.$ $14.78, P=0.001$ ). Total plant biomass (mean $12.56 \mathrm{~g}$ ) was not significantly affected by PSR and DSR $(P>$ $0.20)$; however, it increased in the presence of $P$. pratense $\left(+32 \% ; F_{1,18}=6.66, P=0.02\right)$ and anecic earthworms $\left(+40 \% ; F_{1,16}=22.63, P=0.002\right)$, but it decreased in the presence of Collembola $\left(-16 \% ; F_{1,16}=5.24, P=0.036\right)$ and isopods $\left(-8 \% ; F_{1,16}=6.29, P=0.023\right)$. Shoot-toroot ratio (mean 0.84 ) was significantly affected by the interaction between $\mathrm{PSR}_{\operatorname{lin}}$ and $\operatorname{DSR}_{\operatorname{lin}}\left(F_{1,42}=9.75, P=\right.$ 0.021 ): while the shoot-to-root ratio decreased with plant species richness in the presence of one decomposer species, it differed little in the presence of two and four decomposers (Fig. 1F). Moreover, the shoot-to-root ratio was significantly decreased in the presence of $P$. pratense $\left(-30 \% ; F_{1,17}=9.79, P=0.006\right)$ and in that of anecic earthworms $\left(-19 \% ; F_{1,15}=6.58, P=0.022\right)$.

The ratio of (total) root biomass (mean 0.54 ) in the upper $6 \mathrm{~cm}$ and the lower $14 \mathrm{~cm}$ of the soil profile was marginally significantly affected by an interaction between $\mathrm{PSR}_{\operatorname{lin}}$ and the presence of anecic earthworms $\left(F_{2,41}=5.32, P=0.058\right)$ : While the ratio increased with increasing PSR in the absence of anecic earthworms, it decreased in their presence (Fig. 1G). All other factors had no significant effects on the ratio of root biomass in the upper and lower soil layer (all $P>0.20$ ).

The ${ }^{15} \mathrm{~N}$ signature in spruce needles (overall mean across treatments, 32 atom\%o) increased significantly with DSR ( $\mathrm{DSR}_{\text {cat }}, F_{2,15}=3.67, P=0.050$; $\mathrm{DSR}_{\text {lin }}, F_{1,15}$ $=8.03, P=0.012)$; however, this effect depended on PSR and only occurred when PSR $>1\left(\mathrm{PSR}_{\text {cat }} \times \mathrm{DSR}_{\text {cat }}\right.$ interaction, $F_{4,39}=66.76, P=0.015$; Fig. $1 \mathrm{H}$ ).

\section{Complementarity and selection effects}

Consistent with our second hypothesis, decomposer identity significantly affected net biodiversity and complementarity effects of plants. The net biodiversity effect of plants (mean $0.15 \mathrm{~g} /$ microcosm; of two and four species compared to monocultures) was significantly positive (due to positive net biodiversity effects of mixtures with four plant species). Moreover, it was significantly higher in four plant species mixtures than in two plant species mixtures $\left(F_{1,13}=17.37, P<0.001\right.$; Fig. 2A). While DSR had no significant impact on the net biodiversity effect of plants $\left(F_{1,9}<0.01, P=0.96\right.$; Fig. $2 \mathrm{~A})$, the net biodiversity effect increased significantly from a neutral effect in the absence of anecic earthworms to a positive effect in their presence $\left(F_{1,9}=19.27\right.$, $P=0.002$; Fig. 2B). Moreover, and in contrast to our second hypothesis, the net biodiversity effect of plants was significantly lower in the presence of isopods $(-0.24$ $\pm 0.15 \mathrm{~g} /$ microcosm) than in their absence $(0.46 \pm 0.23$ $\mathrm{g} /$ microcosm; $\left.F_{1,9}=10.89, P=0.009\right)$. The other variables had no significant impacts on the net biodiversity effect (all $P>0.20$ ).

Differences in the net biodiversity effect of plants were mainly due to treatment effects on the complementarity effect (CE; mean $0.097 \mathrm{~g} /$ microcosm). The CE increased with increasing PSR $\left(F_{1,13}=9.95, P=0.008\right.$; Fig. 2 C $)$ and in the presence anecic earthworms $\left(F_{1,8}=13.73, P=\right.$ 0.005 ; Fig. 2D), whereas it decreased in the presence of isopods $(-0.24 \pm 0.15 \mathrm{~g} /$ microcosm $)$ in comparison to their absence $\left(0.46 \pm 0.23 \mathrm{~g} /\right.$ microcosm; $F_{1.8}=11.78, P=$ 0.008). The other variables, e.g., the interaction between PSR and DSR, had no significant impacts on the CE (all $P>0.20)$.

The selection effect (mean $0.054 \mathrm{~g} /$ microcosm) did not change significantly in response to our treatments (all $P$ $>0.20$; Fig. 2E, F). However, there was a tendency towards a higher selection effect in four plant species mixtures than in mixtures containing two plant species in the presence of two and four decomposers, whereas the opposite pattern was true in the presence of one decomposer species $\left(\mathrm{PSR} \times \mathrm{DSR}_{\operatorname{lin}}\right.$ interaction, $F_{1,27}=$ 45.62, $P=0.094$; Fig. 2E).

The SEM approach supported our third hypothesis in part by showing that decomposer effects on plant complementarity were largely due to changes in the proportion of deep roots, litter decomposition, and, to a lesser extent, $\mathrm{N}$ uptake.

A chi-squared test indicated that our hypothesized SEM model cannot be rejected as a potential explana- 

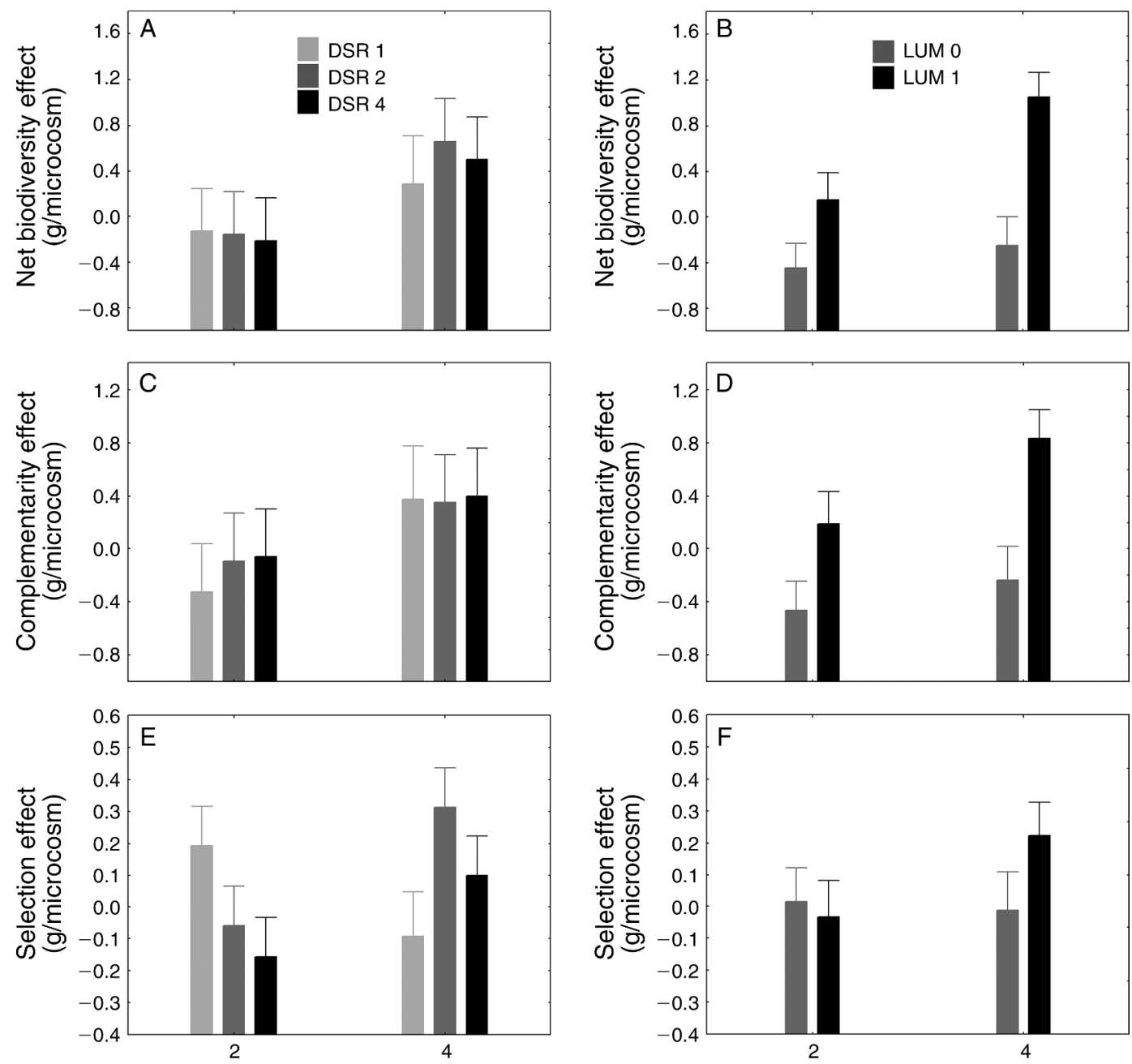

Plant species richness

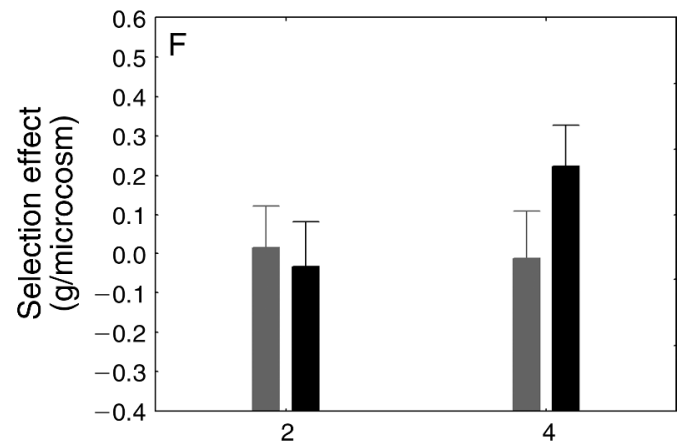

Plant species richness

FIG. 2. Effects (mean $+\mathrm{SE}$ ) of herbaceous plant species richness (PSR; one, two, and four species) and (A, C, E) decomposer species richness (DSR; one, two, and four species) or (B, D, F) presence of the anecic earthworm species Lumbricus terrestris (LUM; 0, absent; 1, present) on (A, B) net biodiversity effect $\left(\mathrm{PSR}^{* * *}, \mathrm{DSR}^{\mathrm{ns}}, \mathrm{LUM}^{* * *}, \mathrm{PSR} \times \mathrm{DSR}^{\mathrm{ns}}, \mathrm{PSR} \times \mathrm{LUM}^{\mathrm{ns}}\right),(\mathrm{C}, \mathrm{D})$ complementarity effect $\left(\mathrm{PSR}^{* * *}, \mathrm{DSR}^{\mathrm{ns}}, \mathrm{LUM}^{* * *}, \mathrm{PSR} \times \mathrm{DSR}^{\mathrm{ns}}, \mathrm{PSR} \times \mathrm{LUM}^{\mathrm{ns}}\right)$, and $(\mathrm{E}, \mathrm{F})$ selection effect $\left(\mathrm{PSR}^{\mathrm{ns}}, \mathrm{DSR}^{\mathrm{ns}}\right.$, $\left.\mathrm{LUM}^{\mathrm{ns}}, \mathrm{PSR} \times \mathrm{DSR} \dagger, \mathrm{PSR} \times \mathrm{LUM}^{\mathrm{ns}}\right)$ in plant shoot productivity. Means are shown with standard error.

$* * * P<0.001 ; \dagger P<0.1$; ns, not significant.

tion of the observed covariance matrix $\left(\chi_{8}^{2}=3.79, P=\right.$ 0.88 ; AIC $=43.79$ ). This suggests that much of the variance in the CE $(76 \%)$ can be explained by PSR, presence of anecic earthworms, and presence of isopods (Table 1, Fig. 3; Appendix: Fig. A1). More specifically, the presence of anecic earthworms and isopods accounted for approximately three-quarters of the explained variance in $\mathrm{CE}$ (Fig. 3). The endogenous variables proportion of deep roots (positive relationship) and surface-litter biomass (negative relationship) determined $\mathrm{CE}$ significantly. The positive relationship between $\mathrm{N}$ uptake and CE was not significant, but explained part of the variance in CE. PSR exerted a direct positive effect on $\mathrm{CE}$, but had minor indirect effects through proportion of deep roots and surface-litter biomass. Presence of isopods had a direct negative effect on $\mathrm{CE}$, as well as a marginally significant indirect negative effect through reducing the proportion of deep roots. Moreover, by reducing surface-litter biomass and by significantly increasing $\mathrm{N}$ uptake, presence of isopods also had an indirect positive effect on CE. Presence of anecic earthworms induced a significantly higher proportion of deep roots, a significantly reduced amount of surfacelitter biomass, and marginally increased $\mathrm{N}$ uptake, which all increased CE. DSR (exogenous variable) and microbial biomass (endogenous variable) did not stay in the final SEM (not shown).

Effects of anecic earthworms and isopods on net biodiversity effects of plants were mainly due to interactions with $P$. pratense and $P$. lanceolata. While 
TABLE 1. Results of structural equation models.

\begin{tabular}{lccrr}
\hline \hline \multicolumn{1}{c}{ Variables } & Estimate & SE & CR & $P$ \\
\hline A) Plant complementarity & & & & \\
Surface litter $\leftarrow$ plant species richness & 0.131 & 0.088 & 1.488 & 0.137 \\
Deep roots $\leftarrow$ plant species richness & 0.218 & 0.261 & 0.836 & 0.403 \\
Deep roots $\leftarrow$ presence anecics & $\mathbf{1 . 3 9 2}$ & $\mathbf{0 . 5 2 2}$ & $\mathbf{2 . 6 6 5}$ & $\mathbf{0 . 0 0 8}$ \\
Surface litter $\leftarrow$ presence anecics & $-\mathbf{1 . 3 0 1}$ & $\mathbf{0 . 1 7 6}$ & $-\mathbf{7 . 3 9 4}$ & $<\mathbf{0 . 0 0 1}$ \\
Surface litter $\leftarrow$ presence isopods & $-\mathbf{0 . 4 4 0}$ & $\mathbf{0 . 1 7 6}$ & $-\mathbf{2 . 5 0 3}$ & $\mathbf{0 . 0 1 2}$ \\
Deep roots $\leftarrow$ presence isopods & -0.988 & 0.522 & -1.891 & 0.059 \\
N uptake $\leftarrow$ presence anecics & 0.117 & 0.126 & 0.933 & 0.351 \\
$N$ uptake $\leftarrow$ presence isopods & 0.232 & 0.126 & 1.844 & 0.065 \\
CE $\leftarrow$ deep roots & $\mathbf{0 . 1 9 7}$ & $\mathbf{0 . 0 5 2}$ & $\mathbf{3 . 8 1 7}$ & $<\mathbf{0 . 0 0 1}$ \\
CE $\leftarrow$ surface litter & $-\mathbf{0 . 3 8 8}$ & $\mathbf{0 . 1 0 0}$ & $-\mathbf{3 . 8 8 0}$ & $<\mathbf{0 . 0 0 1}$ \\
CE $\leftarrow$ plant species richness & $\mathbf{0 . 2 2 1}$ & $\mathbf{0 . 0 7 7}$ & $\mathbf{2 . 8 6 4}$ & $\mathbf{0 . 0 0 4}$ \\
CE $\leftarrow$ uptake & 0.311 & 0.215 & 1.442 & 0.149 \\
CE $\leftarrow$ presence isopods & $\mathbf{0 . 6 8 3}$ & $\mathbf{0 . 1 6 8}$ & $-\mathbf{4 . 0 5 6}$ & $<\mathbf{0 . 0 0 1}$ \\
B) Ecosystem multifunctionality (EMF) & & & & \\
EMF $\leftarrow$ presence T. pratense & $\mathbf{0 . 0 8 8}$ & $\mathbf{0 . 0 4 1}$ & $\mathbf{2 . 1 4 9}$ & $\mathbf{0 . 0 3 2}$ \\
EMF $\leftarrow$ presence $P$. pratense & 0.06 & 0.039 & 1.523 & 0.128 \\
EMF $\leftarrow$ decomposer species richness & 0.027 & 0.015 & 1.83 & 0.067 \\
EMF $\leftarrow$ presence anecics & $\mathbf{0 . 2 5 2}$ & $\mathbf{0 . 0 3 7}$ & $\mathbf{6 . 8 9}$ & $<\mathbf{0 . 0 0 1}$ \\
EMF $\leftarrow$ plant species richness & -0.024 & 0.019 & -1.276 & 0.202 \\
\hline
\end{tabular}

Notes: The effects of (A) herbaceous plant species richness, presence of isopods, and presence of anecic earthworms on proportion of deep roots, $\mathrm{N}$ uptake, surface-litter biomass, and complementarity effect (CE) illustrated in Fig. 3 and the Appendix (Fig. A1); and (B) plant species richness, decomposer species richness, presence of $T$. pratense, $P$. pratense, and anecic earthworms on ecosystem multifunctionality (EMF) illustrated in Fig. 4 and the Appendix (Fig. A2) are shown. Arrows indicate the direction of effect. Given are the unstandardized path coefficients (estimates), standard error of regression weight (SE), the critical value for regression weight (CR; $z=$ estimate/SE), and the level of significance for regression weight $(P)$. For more information on exogenous and endogenous variables see the Methods: Statistical analyses section, and for information on model fit see the Results section. Significant relationships $(P<0.05)$ are shown in boldface type; marginally significant relationships $(P<0.1)$ are given in italics.

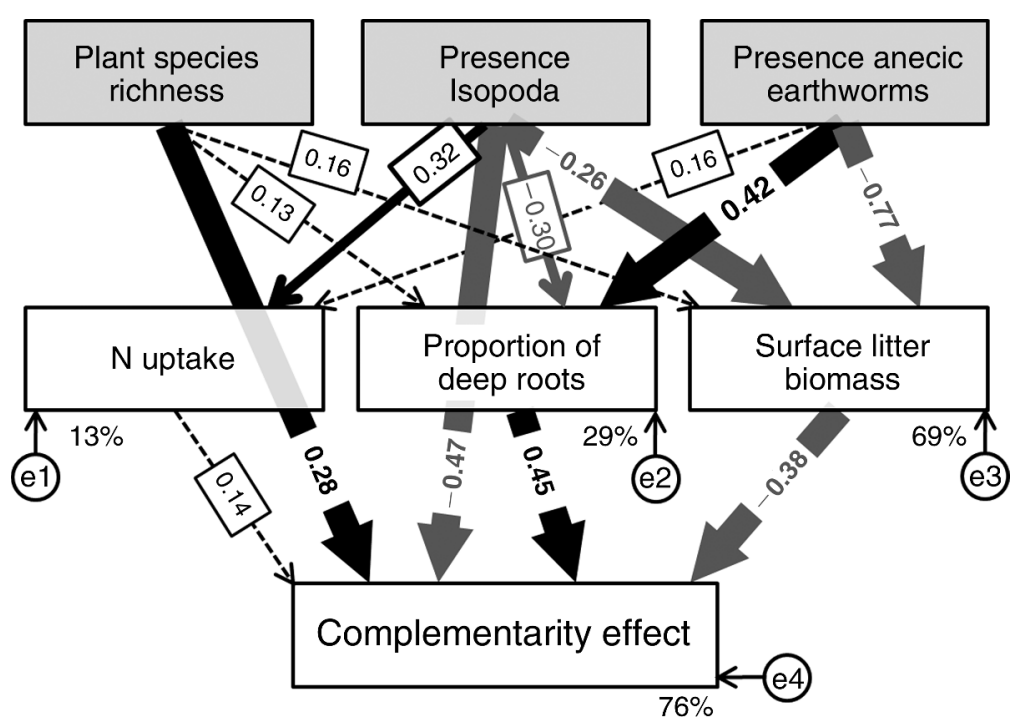

FIG. 3. Structural equation model of herbaceous plant diversity and decomposer identity effects on the complementarity effect of plants. Causal influences of plant species richness (one, two, and four species), presence of isopods and presence of anecic earthworms ( 0 , absent; 1 , present) (exogenous variables; in gray rectangles) on $\mathrm{N}$ uptake, proportion of deep roots, surface-litter biomass, and complementarity effect (endogenous variables; in white rectangles). The data did not significantly deviate from the model: $\chi_{8}^{2}=3.79, P=0.88$. Numbers on arrows are standardized path coefficients. Black (positive) and gray (negative), thick and thin arrows indicate significant $(P<0.05)$ and marginally significant $(P<0.1)$ standardized path coefficients, respectively; thin dashed arrows indicate nonsignificant path coefficients $(P>0.1)$. Circles indicate error terms (e1-e4). Percentages close to endogenous variables indicate the variance explained by the model $\left(R^{2}\right)$. 

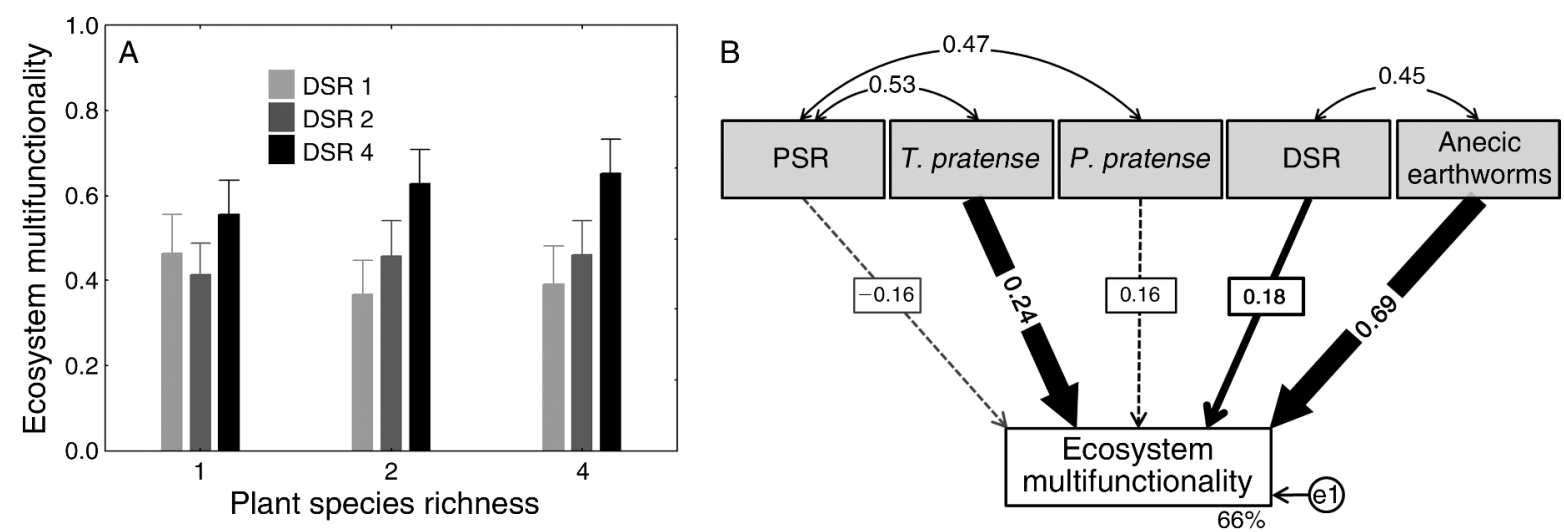

FIG. 4. (A) Effects (mean + SE) of herbaceous plant species richness (PSR; one, two, and four species) and decomposer species richness (DSR; one, two, and four species) on ecosystem multifunctionality (see Methods and Results sections for details; PSR ${ }^{\mathrm{ns}}$, $\mathrm{DSR}^{* * *}, \mathrm{PSR} \times \mathrm{DSR} * *$ ). (B) Structural equation model of herbaceous PSR, DSR, presence of Trifolium pratense, Phleum pratense, and anecic earthworms (0, absent; 1 , present) (exogenous variables; in gray rectangles) on ecosystem multifunctionality. The data did not significantly deviate from the model: $\chi_{7}^{2}=3.17, P=0.87$. Numbers on arrows are standardized path coefficients. Black (positive) and gray (negative) thick and thin arrows indicate significant $(P<0.05)$ and marginally significant $(P<0.1)$ standardized path coefficients, respectively; thin dashed arrows indicate nonsignificant path coefficients $(P>0.1)$. Circles indicate error terms (e1). Percentage close to the endogenous variable indicates the variance explained by the model $\left(R^{2}\right)$.

** $P<0.01 ; * * * P<0.001 ;$ ns, not significant.

the presence of anecic earthworms and isopods did not significantly affect the relative yield of $C$. canadensis, $L$. venosus, and $T$. pratense (all $P>0.15$ ), the relative yield of $P$. pratense was marginally significantly lower in the presence of isopods $(-0.13 \pm 0.06 \mathrm{~g})$ than in their absence $(0.11 \pm 0.12 \mathrm{~g}, P=0.076)$. By contrast, the relative yields of $P$. pratense and $P$. lanceolata were significantly higher in the presence of anecic earthworms $(0.09 \pm 0.08 \mathrm{~g}$ and $0.56 \pm 0.17 \mathrm{~g}$, respectively) than in their absence $(-0.23 \pm 0.05 \mathrm{~g}, P=0.01 ;-0.14 \pm 0.03 \mathrm{~g}$, $P=0.004$, respectively).

\section{Ecosystem multifunctionality}

Consistent with our first hypothesis, ecosystem multifunctionality was affected by a significant interaction between PSR and DSR $\left(F_{1,42}=20.24, P=0.004\right.$; main effect of PSR, $F_{1,16}=0.92, P=0.35$; main effect of DSR, $F_{1,15}=16.64, P=0.001$; Fig. 4A). Ecosystem multifunctionality increased linearly with DSR in the presence of two and four plant species, but was little affected in the presence of one plant species. Moreover, ecosystem multifunctionality increased significantly in the presence of $T$. pratense $\left(+23 \% ; F_{1,16}=12.42, P=0.003\right), P$. pratense $\left(+9 \% ; F_{1,16}=6.91, P=0.018\right)$, and anecic earthworms $\left(+89 \% ; F_{1,15}=31.99, P<0.001\right)$.

A chi-squared test indicated that our hypothesized SEM model cannot be rejected as a potential explanation of the observed covariance matrix $\left(\chi_{7}^{2}=3.17, P=\right.$ 0.87; AIC $=31.17$ ). This suggests that much of the variance in the ecosystem multifunctionality $(66 \%)$ can be explained by PSR, DSR, presence of $T$. pratense, $P$. pratense, and anecic earthworms (Table 1, Fig. 4; Appendix: Fig. A2). More specifically, ecosystem multifunctionality increased significantly in the presence of $T$. pratense and anecic earthworms (Fig. 4B). Moreover, it increased marginally significantly with DSR, indicating that the DSR effect did not solely rely on the presence of anecic earthworms. PSR and presence of $P$. pratense did not affect ecosystem multifunctionality significantly, but stayed in the final SEM.

\section{DisCusSION}

Our results suggest that the diversity and composition of the soil decomposer community influence plant diversity effects on ecosystem processes and ecosystem multifunctionality (Fig. 1). Moreover, decomposer identity effects strongly influenced complementarity between plants (Fig. 2) by changing $\mathrm{N}$ uptake, plant root depth distribution, and surface-litter removal (Fig. 3). Such information is critical to understanding plant diversity effects on ecosystem functioning (Balvanera et al. 2006), including how they increase with time in terrestrial biodiversity experiments (e.g., Cardinale et al. 2007, Fargione et al. 2007, Reich et al. 2012), which could be partly due to the time lag of positive soil feedback effects of slowly maturing decomposer communities (Eisenhauer 2012; N. Eisenhauer, S. Scheu, and P. B. Reich, unpublished manuscript). Moreover, our results support the notion that the exclusively plantcentered view of many previous experiments limits the mechanistic understanding of the BEF relationship (Bever et al. 2010, Miki et al. 2010), and that ecosystem responses to changing biodiversity are more complex than often assumed (Naeem et al. 2000). For instance, plant complementarity effects increased from neutral in the absence of anecic earthworms to significantly positive in the presence of these decomposers. In line with a study using green algae and decomposer bacteria (Naeem et al. 2000), we show that various ecosystem processes are joint functions of plant and decomposer 


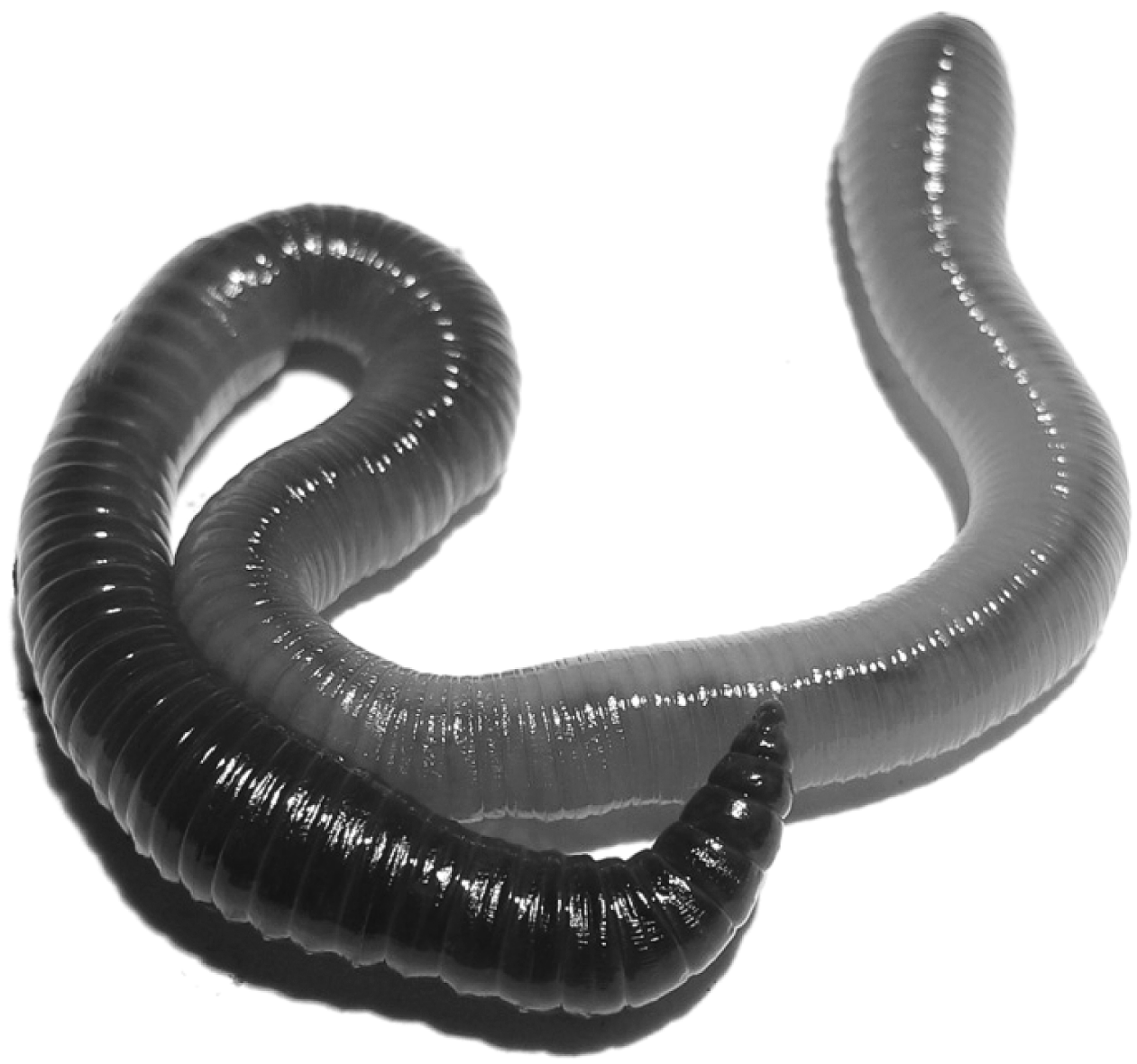

Plate 1. One of the five decomposer animal species (the anecic earthworm Lumbricus terrestris) used in the present experiment. The presence of this species increased plant productivity and complementarity by enhancing surface litter decomposition and facilitating deeper rooting of plants. Photo credit: N. Eisenhauer.

diversity, and moreover, suggest that ecosystem multifunctionality (Hector and Bagchi 2007, Gamfeldt et al. 2008, Zavaleta et al. 2010) is driven, at least in part, by the decomposer community.

There is considerable evidence that biodiversity influences ecosystem functioning (Balvanera et al. 2006, Cardinale et al. 2011, Isbell et al. 2011). Most previous BEF studies used grassland plant communities as model systems (Cardinale et al. 2011, Eisenhauer 2012) and those with durations of more than five years found increasing plant diversity and complementarity effects over time (Cardinale et al. 2007, Fargione et al. 2007, Reich et al. 2012), though the underlying mechanisms are not well understood. One explanation for incremental plant diversity effects is that soil biotic communities and feedback effects have to materialize after establishment of the experiment (Eisenhauer et al. 2010). This notion experienced recent support by evidence for the biological significance of both negative and positive soil feedback effects in shaping the relationship between plant diversity and productivity; the former due to the accumulation of pathogens in species-poor plant communities (Maron et al. 2011,
Schnitzer et al. 2011), and the latter due to higher densities of plant growth promoting bacteria (Latz et al. 2012) and positive impacts on $\mathrm{N}$ cycling and soil $\mathrm{N}$ availability (Reich et al. 2012). Moreover, diversity of soil mutualists may promote plant coexistence and community productivity (van der Heijden et al. 1998, Wagg et al. 2011). Decomposer density and diversity have recently been shown to significantly increase with plant diversity (Scherber et al. 2010, Eisenhauer et al. 2011), raising the question if decomposers contribute to the positive plant diversity-productivity relationship (Eisenhauer 2012).

Indeed, the present results suggest that surface-litter decomposition (Fig. 1A) and community productivity (Fig. 1C) are most pronounced at high plant and decomposer diversity, resulting in maximal ecosystem multifunctionality (Fig. 4). Decomposer diversity and the identity of key decomposer species increased surfacelitter removal and plant $\mathrm{N}$ uptake, thereby most likely increasing resource availability (e.g., perhaps by providing different $\mathrm{N}$ forms) for the plant community. Elevated nutrient availability, in turn, may have relaxed interspecific plant competition. Two findings support 
this interpretation: First, the common negative relationship between plant diversity and individual plant biomass production (Schmidtke et al. 2010) did only occur in the presence of species-poor decomposer communities, whereas spruce biomass was not significantly affected by plant diversity in the presence of four decomposers (Fig. 1D). Second, shoot-to-root ratio decreased with increasing plant diversity in the presence of only one decomposer species, indicating more investment in belowground organs (Bessler et al. 2009), whereas the opposite pattern was found in the presence of more decomposer species (Fig. 1F). Notably, while higher availability of only few resources may increase plant competition and decrease diversity (Harpole and Tilman 2007), elevated diversity of nutrient forms due to the action of decomposers may favor plant complementarity (Eisenhauer 2012).

In line with previous studies (Cardinale et al. 2007, Fargione et al. 2007), net biodiversity effects increased with plant diversity, which was mostly due to complementarity effects (Fig. 2). Using SEM, we were able to explain $76 \%$ of the variance in complementarity effect considering (in addition to plant species richness effects) decomposer identity effects and the processes they mediate (Fig. 3). While plant species richness only had a significant direct impact on the complementarity effect, most likely representing varying functional characteristics of the different plant species, presence of isopods and anecic earthworms increased $\mathrm{N}$ uptake and surface-litter decomposition, both increasing the complementarity effect. In addition, the presence of anecic earthworms allowed plants to root deeper, which may have increased habitat space (Dimitrakopoulos and Schmid 2004) and increased plant complementarity (Eisenhauer 2012). Vertical earthworm burrows, such as those formed by $L$. terrestris, represent channels allowing deeper root penetration, particularly in hard, unbroken ground (Logsdon and Linden 1992) with high nutrient content, microbial enzyme activity, and fast $\mathrm{C}$ turnover rates (Tiunov and Scheu 1999, Don et al. 2008). The relative yields of $P$. pratense and $P$. lanceolata increased significantly in the presence of anecic earthworms, indicating that non-leguminous plant species respond positively to the presence of decomposers. Presence of isopods also had a direct negative effect on the complementarity effect (mainly due to a negative effect on $P$. pratense) and decreased the proportion of deep roots. The reason for these effects remains unclear and need further attention, but we suggest that by feeding on litter material and soil microorganisms they may have changed microbial community composition. The gross measure soil microbial biomass did not explain effects of isopod presence on plant complementarity.

Complementarity effects summarize species interactions, including competition and facilitation of species (Loreau and Hector 2001). Species can be complementary in resource use due to trait differences (Loreau et al.
2001, Reich et al. 2012), i.e., due to different resource niches (Tilman et al. 1997), where niches can be defined on chemical, spatial, and temporal scales (McKane et al. 2002, Ashton et al. 2010). The present study indicates that decomposers significantly impact chemical and spatial niches for plants, modifying the net outcomes of plant species interactions. Notably, the short-term character of the study did not allow the study of temporal niches, but also eliminates the complexity of long-term studies where both "short-term" effects and long-term plant-soil feedback effects can occur, and be difficult to separate.

There are also additional potential mechanisms how decomposers could affect plant complementarity in natural plant communities. For instance, some decomposers, such as earthworms and collembolans, have been shown to reduce the pathogen load of plants by ingesting and digesting plant pathogenic microbes and nematodes (Sabatini et al. 2002, Wurst 2010) and by changing plant resistance to parasites (Blouin et al. 2005), thereby most likely also affecting the "pathogen niche" (Petermann et al. 2008). In addition to the mechanisms observed in the present paper, future studies thus should investigate if decomposer diversity/ identity changes the interplay between soil mutualist and antagonist feedback effects (Eisenhauer 2012).

The present study shows that plant diversity effects can occur even in highly controlled environments with little opportunity for spatiotemporal resource partitioning. This experimental setup allowed us to rigorously test the role of decomposers in this context and reveals that positive complementarity effects only occurred in the presence of key decomposers. We posit that decomposers relax interspecific plant competition by enlarging chemical and spatial habitat space and thereby facilitate plant complementarity (e.g., Ashton et al. 2010). Thus, elevated decomposer performance at high plant diversity (Scherber et al. 2010, Eisenhauer et al. 2011) is likely to positively feed back to plant community performance and may contribute to the positive relationship between plant diversity and ecosystem functioning as well as ecosystem multifunctionality.

\section{ACKNOWLEDGMENTS}

We thank Cindy Buschena, Artur Stefanski, Montara Roberts, Chris Bergquist, Elina Eisenhauer, and Susan Barrott (University of Minnesota) for their help during the experiment. Further, we thank Stefan Scheu and Ingrid Kleinhans (University of Göttingen) for soil microbial measurements. Constructive comments by two anonymous reviewers improved the manuscript. N. Eisenhauer gratefully acknowledges funding by the Deutsche Forschungsgemeinschaft (DFG, German Research Foundation; Ei 862/1-1), and P. B. Reich gratefully acknowledges support from the Department of Energy (DOE/ DE-FG02-96ER62291) and the National Science Foundation (NSF Biocomplexity 0322057, NSF LTER DEB 9411972 (1994-2000), DEB 0080382 (2000-2006), and DEB 0620652 (2006-2012), and NSF LTREB 0716587). Further, P. B. Reich acknowledges support from the Department of Energy, Office of Science (BER) through the Midwestern Regional Center of 
the National Institute for Climatic Change Research at Michigan Technological University (DE-FC02-06ER64158).

\section{Literature Cited}

Anderson, J. P. E., and K. H. Domsch. 1978. A physiological method for the quantitative measurement of microbial biomass in soil. Soil Biology and Biochemistry 10:215-221.

Arbuckle, J. L. 2003. Amos 5.0. Update to the Amos user's guide. SmallWaters, Chicago, Illinois, USA

Ashton, I. W., A. E. Miller, W. D. Bowman, and K. N. Suding. 2010. Niche complementarity due to plasticity in resource use: plant partitioning of chemical $\mathrm{N}$ forms. Ecology 91:3252-3260.

Balvanera, P., A. B. Pfisterer, N. Buchmann, J.-S. He, T. Nakashizuka, D. Raffaelli, and B. Schmid. 2006. Quantifying the evidence for biodiversity effects on ecosystem functioning and services. Ecology Letters 9:1146-1156.

Bardgett, R. D., and D. A. Wardle. 2010. Abovegroundbelowground linkages, biotic interactions, ecosystem processes, and global change. Oxford Series in Ecology and Evolution. Oxford University Press, New York, USA.

Bessler, H., V. M. Temperton, C. Roscher, N. Buchmann, B. Schmid, E.-D. Schulze, W. W. Weisser, and C. Engels. 2009. Aboveground overyielding in grassland mixtures is associated with reduced biomass partitioning to belowground organs. Ecology 90:1520-1530.

Bever, J. D., I. A. Dickie, E. Facelli, J. M. Facelli, J. Kliromonos, M. Moora, M. C. Rillig, W. D. Stock, M. Tibbett, and M. Zobel. 2010. Rooting theories of plant community ecology in microbial interactions. Trends in Ecology and Evolution 25:468-478.

Blouin, M., Y. Zuily-Fodil, A. T. Pham-Thi, D. Laffray, G. Reversat, A. Pando, J. Tondoh, and P. Lavelle. 2005. Belowground organism activities affect plant aboveground phenotype, inducing plant tolerance to parasites. Ecology Letters 8:202-208.

Bruno, J. F., K. E. Boyer, J. E. Duffy, and S. C. Lee. 2008. Relative and interactive effects of plant and grazer richness in a benthic marine community. Ecology 89:2518-2528.

Butchart, S. H. M., et al. 2010. Global biodiversity: indicators of recent declines. Science 328:1164-1168.

Cardinale, B. J., K. L. Matulich, D. U. Hooper, J. E. Byrnes, E. Duffy, L. Gamfeldt, P. Balvanera, M. I. O'Connor, and A. Gonzalez. 2011. The functional role of producer diversity in ecosystems. American Journal of Botany 98:572-592.

Cardinale, B. J., J. P. Wright, M. W. Cadotte, I. T. Carroll, A. Hector, D. S. Srivastava, M. Loreau, and J. J. Weis. 2007. Impacts of plant diversity on biomass production increase through time because of species complementarity. Proceedings of the National Academy of Sciences USA 104:1812318128.

Dimitrakopoulos, P. G., and B. Schmid. 2004. Biodiversity effects increase linearly with biotope space. Ecology Letters 7:574-583.

Don, A., B. Steinberg, I. Schöning, K. Prtisch, M. Joschko, G. Gleixner, and E.-D. Schulze. 2008. Organic carbon sequestration in earthworm burrows. Soil Biology and Biochemistry 40:1803-1812.

Duffy, J. E. 2009. Why biodiversity is important to the functioning of real-world ecosystems. Frontiers in Ecology and Environment 7:437-444.

Eisenhauer, N. 2012. Aboveground-belowground interactions as a source of complementarity effects in biodiversity experiments. Plant and Soil 351:1-22.

Eisenhauer, N., et al. 2010. Plant diversity effects on soil microorganisms support the singular hypothesis. Ecology 91:485-496.

Eisenhauer, N., et al. 2011. Plant diversity surpasses plant functional groups and plant productivity as driver of soil biota in the long term. PLoS ONE 6:e16055.
Eisenhauer, N., N. A. Fisichelli, L. E. Frelich, and P. B. Reich. 2012. Interactive effects of global warming and 'global worming' on the intial establishment of native and exotic herbaceous plant species. Oikos. http://dx.doi.org/10.1111/j. 1600-0706.2011.19807.x

Eisenhauer, N., A. Milcu, N. Nitschke, A. C. W. Sabais, C. Scherber, and S. Scheu. 2009. Earthworm and belowground competition effects on plant productivity. Oecologia 161:291-301.

Eisenhauer, N., A. Milcu, A. C. W. Sabais, and S. Scheu. 2008. Animal ecosystem engineers modulate the diversity-invasibility relationship. PLoS ONE 3:e3489.

Fargione, J. E., D. Tilman, R. Dybzinski, J. HilleRisLambers, C. Clark, W. S. Harpole, J. M. H. Knops, P. B. Reich, and M. Loreau. 2007. From selection to complementarity: shifts in the causes of biodiversityproductivity relationships in a long-term biodiversity experiment. Proceedings of the Royal Society B 274:871-876.

Fornara, D. A., and D. Tilman. 2009. Ecological mechanisms associated with the positive diversity-productivity relationship in an N-limited grassland. Ecology 90:408-418.

Fründ, H.-C., K. Butt, Y. Capowiez, N. Eisenhauer, C. Emmerling, G. Ernst, M. Potthoff, M. Schädler, and S. Schrader. 2010. Using earthworms as model organisms in the laboratory: recomendations for experimental implementations. Pedobiologia 53:119-125.

Gamfeldt, L., H. Hillebrand, and P. R. Jonsson. 2008. Multiple functions increase the importance of biodiversity for overall ecosystem functioning. Ecology 89:1223-1231.

Gilliam, F. S. 2007. The ecological significance of the herbaceous layer in temperate forest ecosystems. BioScience 57:845-858.

Grace, J. B. 2006. Structural equation modeling and natural systems. Cambridge University Press, Cambridge, UK.

Harpole, W. S., and D. Tilman. 2007. Grassland species loss resulting from reduced niche dimension. Nature 446:791-793.

Hector, A., and R. Bagchi. 2007. Biodiversity and ecosystem multifunctionality. Nature 448:188-191.

Heemsbergen, D. A., M. P. Berg, M. Loreau, J. R. van Hal, J. H. Faber, and H. A. Verhoef. 2004. Biodiversity effects on soil processes explained by interspecific functional dissimilarity. Science 306:1019-1020.

Huhta, V., D. H. Wright, and D. C. Coleman. 1989. Characteristics of defaunated soil. I. A comparison of three techniques applied to two different forest soils. Pedobiologia 33:415-424.

Isbell, F., et al. 2011. High plant diversity is needed to maintain ecosystem services. Nature 477:199-202.

Kempson, D., M. Lloyd, and R. Ghelardij. 1963. A new extractor for woodland litter. Pedobiologia 3:1-21.

Klironomos, J. N., J. McCune, M. Hart, and J. Neville. 2000. The influence of arbuscular mycorrhizae on the relationship between plant diversity and productivity. Ecology Letters $3: 137-141$.

Latz, E., N. Eisenhauer, E. Allan, C. Roscher, S. Scheu, and A. Jousset. 2012. Plant diversity improves protection against soil-borne pathogens by fostering antagonistic bacterial communities. Journal of Ecology 100:597-604.

Logsdon, S. D., and D. R. Linden. 1992. Interactions of earthworms with soil physical conditions influencing plant growth. Soil Science 154:330-337.

Loreau, M. 2001. Microbial diversity, producer-decomposer interactions and ecosystem processes: a theoretical model. Proceedings of the Royal Society B 268:303-309.

Loreau, M., and A. Hector. 2001. Partitioning selection and complementarity in biodiversity experiments. Nature 412:7276.

Loreau, M., S. Naeem, P. Inchausti, J. Bengtsson, J. P. Grime, A. Hector, D. U. Hooper, M. A. Huston, D. Raffaelli, B. Schmid, D. Tilman, and D. A. Wardle. 2001. Biodiversity 
and ecosystem functioning: current knowledge and future challenges. Science 294:804-808.

Maron, J. L., M. Marler, J. N. Kliromonos, and C. C. Cleveland. 2011. Soil fungal pathogens and the relationship between plant diversity and productivity. Ecology Letters 14:36-41.

McKane, R. B., L. C. Johnson, G. R. Shaver, K. J. Nadelhoffer, E. B. Rastetter, B. Fry, A. E. Giblin, K. Kielland, B. L. Kwiatkowski, J. A. Laundre, and G. Murray. 2002. Resource-based niches provide a basis for plant species diversity and dominance in arctic tundra. Nature 415:68-71.

Miki, T., M. Ushido, S. Fukui, and M. Kondoh. 2010. Functional diversity of microbial decomposers facilitates plant coexistence in a plant-microbe-soil feedback model. Proceedings of the National Academy of Sciences USA 107:14251-14256.

Mikola, J., R. D. Bardgett, and K. Hedlund. 2002. Biodiversity, ecosystem functioning and soil decomposer food webs. Pages 169-180 in M. Loreau, S. Naeem, P. Inchausti, editors. Biodiversity and ecosystem functioning: synthesis and perspectives. Oxford University Press, Oxford, UK.

Milcu, A., S. Partsch, C. Scherber, W. W. Weisser, and S. Scheu. 2008. Earthworms and legumes control litter decomposition in a plant diversity gradient. Ecology 89:1872-1882.

Moran, M. D. 2003. Arguments for rejecting the sequential Bonferroni in ecological studies. Oikos 100:403-405.

Mouillot, D., S. Villéger, M. Scherer-Lorenzen, and N. W. H. Mason. 2011. Functional structure of biological communities predicts ecosystem multifunctionality. PLoS ONE 6:e17476.

Mulder, C. P. H., J. Koricheva, K. Huss-Danell, P. Högberg, and J. Joshi. 1999. Insects affect relationships between plant species richness and ecosystem processes. Ecology Letters 2:237-246.

Naeem, S., D. R. Hahn, and G. Schuurman. 2000. Producerdecomposer co-dependency influences biodiversity effects. Nature 403:762-764.

Partsch, S., A. Milcu, and S. Scheu. 2006. Decomposers (Lumbricidae, Collembola) affect plant performance in model grasslands of different diversity. Ecology 87:25482558.

Petermann, J. S., A. Fergus, L. A. Turnbull, and B. Schmid. 2008. Janzen-Connell effects are widespread and strong enough to maintain diversity in grasslands. Ecology 89:2399-2406.

Reich, P. B., D. Tilman, F. Isbell, K. E. Mueller, S. E. Hobbie, D. F. B. Flynn, and N. Eisenhauer. 2012. Impacts of biodiversity loss escalate through time as redundancy fades. Science 336:589-592.

Sabatini, M. A., P. Grazioso, C. Altomare, and G. Innocenti. 2002. Interactions between Onychiurus armatus and Trichoderma harzianum in take-all disease suppression in a simple experimental system. European Journal of Soil Biology 38:71-74.

SAS Institute. 2003. SAS version 9.1. SAS Institute, Cary, North Carolina, USA.

Scherber, C., et al. 2010. Bottom-up effects of plant diversity on biotic interactions in a biodiversity experiment. Nature 468:553-556.

Scheu, S. 1992. Automated measurement of the respiratory response of soil microcompartments: Active microbial biomass in earthworm faeces. Soil Biology and Biochemistry 24:1113-1118.

Schmid, B., and A. Hector. 2004. The value of biodiversity experiments. Basic and Applied Ecology 5:535-542.

Schmidtke, A., T. Rottstock, U. Gaedke, and M. Fischer. 2010. Plant community diversity and composition affect individual plant performance. Oecologia 164:665-677.

Schnitzer, S., J. Klironomos, J. HilleRisLambers, L. Kinkle, P. B. Reich, K. Xiao, M. Rillig, B. Sikes, R. Callaway, S. Mangan, E. Van Nes, and M. Scheffer. 2011. Soil microbes drive the classic plant diversity-productivity pattern. Ecology 92:296-303.

Tilman, D., C. L. Lehman, and K. T. Thomson. 1997. Plant diversity and ecosystem productivity: theoretical considerations. Proceedings of the National Academy of Sciences USA 94:1857-1861.

Tiunov, A. V., and S. Scheu. 1999. Microbial respiration, biomass, biovolume and nutrient status in burrow walls of Lumbricus terrestris L. (Lumbricidae). Soil Biology and Biochemistry 31:2039-2048.

Tiunov, A. V., and S. Scheu. 2005. Facilitative interactions rather than resource partitioning drive diversity-fucntioning relationships in laboratory fungal communities. Ecology Letters 8:618-625.

van der Heijden, M. G. A., J. N. Kliromonos, M. Ursic, P. Moutoglis, R. Streitwolf-Engel, T. Boller, A. Wiemken, and I. R. Sanders. 1998. Myccorhizal fungal diversity determines plant biodiversity, ecosystem variability and productivity. Nature 396:69-72.

Wagg, C., J. Jansa, B. Schmid, and M. G. A. van der Heijden. 2011. Belowground biodiversity effects of plant symbionts support aboveground productivity. Ecology Letters 14:10011009.

Wardle, D. A., and M. Jonsson. 2010. Biodiversity effects in real ecosystems: A response to Duffy. Frontiers in Ecology and Environment 8:10-11.

Wurst, S. 2010. Effects of earthworms on above- and belowground herbivores. Applied Soil Ecology 45:123-130.

Zavaleta, E. S., J. R. Pasari, K. B. Hulvey, and G. D. Tilman. 2010. Sustaining multiple ecosystem functions in grassland requires higher biodiversity. Proceeding of the National Academy of Science USA 107:1443-1446.

\section{Supplemental Material}

\section{Appendix}

Tables showing number of replicates per diversity level, design of the experiment, and final ANOVA models, as well as figures showing the unstandardizard path coefficients in structural equation models 1 and 2 (Ecological Archives E093-209-A1). 